\title{
Mercury determination in petroleum products by electrothermal atomic absorption spectrometry after in situ preconcentration using multiple injections
}

\author{
Walter N. L. dos Santos, ${ }^{* a b}$ Fábio de S. Dias, ${ }^{b}$ Marcio V. Reboucas, ${ }^{c}$ Madson de \\ G. Pereira, ${ }^{d}$ Valfredo A. Lemos ${ }^{e}$ and Leonardo S. G. Teixeira ${ }^{b f}$
}

Received 23rd May 2006, Accepted 8th August 2006

First published as an Advance Article on the web 29th August 2006

DOI: $10.1039 / \mathbf{b 6 0 7 2 7 4 g}$

A simple method for mercury determination in petroleum fractions (e.g. naphtha) using electrothermal atomic absorption spectrometry (ETAAS) associated with multiple injection technique for direct preconcentration in the graphite tube has been developed. Oil-in-water microemulsions (three-component solutions) were prepared using a mixture of sample, propan-1-ol and $\mathrm{HNO}_{3}$. No additional sample pretreatment was required. In the procedure, three successive $30 \mu \mathrm{L}$ micro-emulsion aliquots are delivered to the graphite tube. The pyrolysis and atomization temperatures were set to $400{ }^{\circ} \mathrm{C}$ and $1400{ }^{\circ} \mathrm{C}$, respectively. The calibration curves showed a linear response up to analyte concentrations of $150 \mu \mathrm{g} \mathrm{\textrm {L } ^ { - 1 }}$ with a correlation coefficient of 0.993 . The precision calculated from fifteen consecutive measurements and defined as the coefficient of variation of solutions containing 5.0 and $30 \mu \mathrm{g} \mathrm{L}^{-1}$ of $\mathrm{Hg}$ were $6.4 \%$ and $4.7 \%$, respectively. The limit of detection (LOD), defined as the $\mathrm{Hg}$ concentration that gives a response equivalent to three times the standard deviation $(s)$ of the blank $(n=10)$, was found to be $0.78 \mu \mathrm{g} \mathrm{L}^{-1}$. The proposed procedure was used for mercury determination in naphtha feeds processed in Braskem S.A. (Salvador, Bahia, Brazil).

\section{Introduction}

Determination of trace elements in crude oil and petroleum products has received considerable attention because of its relevance for petroleum cracking and refining processes. ${ }^{1}$ The presence of some elements, such as mercury, may cause corrosion, affecting equipment integrity, or poisoning of the process catalyst. In addition, the presence of mercury affects the product quality, health and safety of workers and the environment. ${ }^{2}$ Mercury in petrochemical products is released during combustion with harmful effects on human health and environment. ${ }^{1}$ Combusted hydrocarbons are identified as major anthropogenic sources of mercury emissions to the atmosphere in the US. ${ }^{3}$

The determination of $\mathrm{Hg}$ in petroleum products is particularly difficult due to the volatile nature of both mercury and

\footnotetext{
${ }^{a}$ Universidade Estadual de Santa Cruz, Departamento de Ciências Exatas e Tecnológicas, Campos Prof. Soane Nazaré de Andrade, Km 16-Rodovia Ilhéus/Itabuna, Ilhéus, Bahia 45662-000, Brazil. E-mail:wnlsantos@uesc.br; Fax: +55-71-3235-5166; Tel: + 55-71-3235-5785

${ }^{b}$ Universidade Federal da Bahia, Instituto de Química, Campus Universitário de Ondina, Salvador, Bahia 40170-290, Brazil

${ }^{c}$ Braskem S. A., Unidade de Insumos Básicos, Rua Eteno 1561, Complexo Petroquímico de Camaçari Bahia 42810-000, Brazil

${ }^{d}$ Universidade do Estado da Bahia, Departamento de Ciencias Exatas e da Terra, Estrada das Barreiras S/N, Salvador, 41195-001, Brazil

${ }^{e}$ Universidade Estadual do Sudoeste da Bahia, Laboratório de Química Analítica, Campus de Jequié, Jequié, Bahia 45200-000, Brazil

${ }^{f}$ Universidades Salvador - UNIFACS, Departamento de Engenharia e Arquitetura, Av. Cardeal da Silva 132, Salvador, Bahia 40220-141, Brazil
}

the matrix which may lead to significant loss of the analyte. In the analytical determinations of metallic elements in petroleum products by atomic spectroscopic techniques, the samples are frequently prepared by dry or wet ashing procedures. ${ }^{4}$ The main drawback of such steps is the possibility of loss of mercury due to the high temperature employed in such procedures. Additionally, trace element losses may also occur through absorption on the walls of the ashing flask and by retention in the acid-insoluble fraction of the ash. ${ }^{1}$ Procedures for determination of $\mathrm{Hg}$ in petroleum products by several analytical techniques are summarized in Table 1.

Some methods, involving atomic spectrometry techniques, have been used for mercury determination in petroleum products. However, these methods are not sensitive enough for direct $\mathrm{Hg}$ determination and a preconcentration step is required. ${ }^{5,6}$ Inductively coupled plasma atomic emission spectrometry (ICP OES) has the disadvantage of spectral interferences susceptibility, which makes accurate trace element determination in complex matrices quite difficult. Additionally, the detection limits of ICP OES techniques are not as good as those obtained by electrothermal atomic absorption spectrometry (ETAAS). Considering the whole analytical procedure, including pretreatment steps, the main advantages of ETAAS are rapidity, simplicity, sensitivity and good precision. $^{1}$

From what has been mentioned, it is evident that simple and efficient methodologies need to be developed for eliminating problems associated with mercury determination in complex samples. Therefore, the present work proposes a method based on direct analyses of this analyte in petroleum products by 
Table 1 Summary of literature references on mercury analysis in petroleum products

\begin{tabular}{|c|c|c|c|c|c|}
\hline Analyte & Sample & $\begin{array}{l}\text { Detection } \\
\text { technique }\end{array}$ & Detection limit & Details & Ref. \\
\hline Total Hg & Gasoline & CV-AAS & $0.10 \mu \mathrm{g} \mathrm{L}^{-1}$ & $\begin{array}{l}\text { Direct aqueous } \mathrm{NaBH}_{4} \text { reduction in a three- } \\
\text { component (microemulsion) medium }\end{array}$ & 12 \\
\hline $\begin{array}{l}\mathrm{Hg}^{0} \text { and } \\
(\mathrm{Me})_{2} \mathrm{Hg}\end{array}$ & Crude oil & CV-AFS & - & $\begin{array}{l}\text { Nonvolatile forms of mercury associated with } \\
\text { asphaltenes were identified using differential } \\
\text { solubility methods. }\end{array}$ & 13 \\
\hline Total $\mathrm{Hg}$ & $\begin{array}{l}\text { Gasoline and diesel } \\
\text { samples }\end{array}$ & CV-AFS & $10 \mathrm{ng} \mathrm{g}^{-1}$ & $\begin{array}{l}\text { Mercury was extracted from these samples by } \\
\mathrm{BrCl} \text { oxidation }\end{array}$ & 14 \\
\hline Total $\mathrm{Hg}$ & $\begin{array}{l}\text { Gasoline, kerosene, } \\
\text { diesel, and crude oil }\end{array}$ & CV-AFS & $0.15 \mathrm{ng} \mathrm{g}^{-1}$ & $\begin{array}{l}\text { The analytical performance of the } \\
\text { combustion/trap technique in different types } \\
\text { of samples at different mercury concentration } \\
\text { levels was statistically compared with wet } \\
\text { extraction methods }\end{array}$ & 15 \\
\hline Total $\mathrm{Hg}$ & $\begin{array}{l}\text { SRM crude oils and } \\
\text { refined products }\end{array}$ & CV-ICP-MS & $10 \mathrm{pg} \mathrm{g}^{-1}$ & $\begin{array}{l}\text { Samples were spiked with stable }{ }^{201} \mathrm{Hg} \text { and } \\
\text { wet ashed in a closed system }\end{array}$ & 16 \\
\hline $\begin{array}{l}\mathrm{Hg}^{0} \\
(\mathrm{Me})_{2} \mathrm{Hg}\end{array}$ & Natural gas condensates & GC-ICP-MS & $\begin{array}{l}0.98 \mu \mathrm{g} \mathrm{L}^{-1} \\
1.32 \mu \mathrm{g} \mathrm{L}^{-1}\end{array}$ & $\begin{array}{l}\text { Two consecutive injections allowing } \\
\text { comprehensive speciation analysis. }\end{array}$ & 17 \\
\hline $\mathrm{MePrHg}$ & & & $0.16 \mu \mathrm{g} \mathrm{L}^{-1}$ & & \\
\hline $\mathrm{Et}_{2} \mathrm{Hg}$ & & & $0.08 \mu \mathrm{g} \mathrm{L}^{-1}$ & & \\
\hline $\mathrm{MeBuHg}$ & & & $0.14 \mu \mathrm{g} \mathrm{L}^{-1}$ & & \\
\hline $\mathrm{Pr}_{2} \mathrm{Hg}$ & & & $0.20 \mu \mathrm{g} \mathrm{L}^{-1}$ & & \\
\hline $\mathrm{Bu}_{2} \mathrm{Hg}$ & & & $0.11 \mu \mathrm{g} \mathrm{L}^{-1}$ & & \\
\hline $\begin{array}{l}\text { Total } \mathrm{Hg}, \mathrm{Hg}(\mathrm{II}) \text {, } \\
\text { and methyl } \mathrm{Hg}\end{array}$ & $\begin{array}{l}\text { Petroleum condensate } \\
\text { and crude oil }\end{array}$ & CVAFS & $0.1 \mathrm{ng} \mathrm{g}^{-1}$ & $\begin{array}{l}\text { Sequence of relatively simple wet chemical } \\
\text { extractions. }\end{array}$ & 18 \\
\hline Total $\mathrm{Hg}$ & Crude oil & CVAFS & $0.2 \mathrm{ng} \mathrm{g}^{-1}$ & $\begin{array}{l}\text { Samples were directly introduced to the } \\
\text { system without the use of chemicals and } \\
\text { complicated digestion procedures. }\end{array}$ & 19 \\
\hline Total $\mathrm{Hg}$ & Naphta & GFAAS & $0.78 \mu \mathrm{g} \mathrm{L}^{-1}$ & $\begin{array}{l}\text { Multiple injection technique for direct } \\
\text { preconcentration in the graphite tube }\end{array}$ & This work \\
\hline
\end{tabular}

using ETAAS associated with multiple injection technique. Multiple injection technique has been applied to in situ preconcentration of several metals and low limits of detection have been reached, dispensing with sample pretreatment steps and speeding up the analysis. ${ }^{7}$

\section{Experimental}

\subsection{Instrumentation}

A Varian SpectrAA 220Z (Mulgrave, Victoria, Australia) Zeeman atomic absorption spectrophotometer equipped with a model GTA 110 graphite tube atomizer, a model PSD 100 auto sampler and Varian hollow cathode lamps ( $\mathrm{Hg} 253.7 \mathrm{~nm})$ were used for all the measurements. The device was set up according to the manufacturer's instructions and run in the single element mode. Pyrolytic graphite-coated tubes with a center-fixed platform (Varian, PN: 63-100026-00) were used. Argon 99.996\% (White Martins, São Paulo, Brazil) was employed as a purge and protective gas.

\subsection{Reagents and solutions}

All reagents were of analytical grade quality and freshly distilled and deionized water (electrical resistivity of 18.0 $\mathrm{M} \Omega \mathrm{cm}^{-1}$ ) was used when necessary.

The working standard solutions of $\mathrm{Hg}$ were prepared by appropriate stepwise dilution of a $1000 \mu \mathrm{g} \mathrm{mL}^{-1}$ (Merck,
Darmstadt, Germany) stock standard solution to the required $\mu \mathrm{g} \mathrm{mL}^{-1}$ levels just before use.

Nitric acid $60 \% \mathrm{v} / \mathrm{v}$ was of ultrapure grade, prepared by diluting concentrated suprapure nitric acid, supplied by Merck (Darmstadt, Germany).

A $1000 \mathrm{mg} \mathrm{L}^{-1}$ stock palladium solution was used as a chemical modifier, co-injecting $20 \mu \mathrm{L}$ with the sample. This solution was prepared in $0.1 \% \mathrm{v} / \mathrm{v} \mathrm{HNO}_{3}$ from a stock solution of $10000 \mathrm{mg} \mathrm{L}^{-1} \mathrm{Pd}\left(\mathrm{NO}_{3}\right)_{2}$ in $c a .15 \% \mathrm{v} / \mathrm{v} \mathrm{HNO}_{3}$ (Merck, Darmstadt, Germany).

Propan-1-ol (Merck) was used as co-solvent and Braskem internal product, known as mixed xylenes, was used as organic blank sample.

\subsection{Samples}

All petroleum products samples (naphtha) were collected into clean bottles and stored in a freezer at $4{ }^{\circ} \mathrm{C}$ prior to analysis, usually performed within three days. The sampling apparatus was cleaned by nitric acid, deionised water and ethanol washings. The samples were collected from the plant's raw material storage tank or directly from carrier ship tanks. Typically, the collected samples presented distillation curves ranging from 30 to $280{ }^{\circ} \mathrm{C}$ and specific gravity values around 0.70 .

\subsection{General analytical procedure}

Previous studies showed the advantage of sample emulsification over acid digestion and sample dilution with organic 
Table 2 Graphite furnace temperature program

\begin{tabular}{lllll}
\hline Cycle & Step & Temperature $/{ }^{\circ} \mathrm{C}$ & Time $/ \mathrm{s}$ & $\begin{array}{l}\text { Argon } \\
\text { flow } / \mathrm{L} \mathrm{min}\end{array}$ \\
\hline Drying & 1 & 40 & 1.0 & 3.0 \\
& 2 & 80 & 5.0 & 3.0 \\
& 3 & 90 & 5.0 & 3.0 \\
& 4 & 120 & 10.0 & 3.0 \\
& 5 & 122 & 3.0 & 3.0 \\
& 6 & 180 & 5.0 & 3.0 \\
Pyrolysis & 7 & 250 & 2.0 & 3.0 \\
& 9 & 400 & 5.0 & 3.0 \\
Atomization & 10 & 400 & 5.0 & 3.0 \\
& 11 & 1400 & 1.0 & 3.0 \\
Cleaning & 13 & 1400 & 2.5 & 0.0 \\
& 13 & 1800 & 2.5 & 0.0 \\
& & & 0.5 & 3.0
\end{tabular}

solvent as the sample preparation procedure for the determination of metals in petroleum products samples. ${ }^{8-10}$ Oil-in-water micro-emulsions (three-component solutions) were prepared using a specific sequence in order to guarantee their stability. In this way, aliquots of $5.0 \mathrm{~mL}$ of sample were placed in $10 \mathrm{ml}$ volumetric flasks, and $2 \mathrm{~mL}$ of propan-1-ol and $500 \mu \mathrm{L}$ of $0.2 \%(\mathrm{v} / \mathrm{v}) \mathrm{HNO}_{3}$ were added. Then, the volumes were made up with propan-1-ol and the mixtures were vigorously manually shaken. One-phase transparent micro-emulsions were obtained. All solutions for the analytical calibration curves and for analyte addition, using inorganic and organic standards, were prepared in the same way as micro-emulsions. Blank solutions were prepared with xylene replacing the sample.

The literature reports the use of a permanent modifier such as palladium, iridium, rhodium and ruthenium, to guarantee the stability of the $\mathrm{Hg}^{11}$ However, our objective was to develop a routine procedure without use of permanent modifier. In this way, $20 \mu \mathrm{L}$ of $1000 \mathrm{mg} \mathrm{L}^{-1}$ palladium solution was co-injected with the sample for the stabilization of mercury. The samples were slowly injected into the graphite tube, where preconcentration takes place. Three successive $30 \mu \mathrm{L}$ sampling aliquots were delivered to the tube and the temperature was raised, leading to partial drying of each aliquot. At each multiple injection, the samples and modifier aliquots were dried through steps 1-7 described in Table 2, before the next injection. After the third injection, the temperature program was completed according to the conditions shown in Table 2 and the total amount of the $\mathrm{Hg}$ was determined from the integrated absorbance signal.

\section{Results and discussion}

Preliminary investigations were carried out in order to optimize the parameters that influence the preparation of the micro-emulsion. Firstly, the emulsion should be homogenous and stable for the time required to perform the measurement, in triplicate. In the order to establish the conditions for the formation of a homogeneous and stable micro-emulsion, the ratio of sample to aqueous solution of nitric acid and propan1-ol (co-solvent) was varied. The micro-emulsion prepared mixing $5.0 \mathrm{~mL}$ of naphtha, $2.0 \mathrm{~mL}$ of propan-1-ol, $500 \mu \mathrm{L}$ of $0.2 \% \mathrm{v} / \mathrm{v} \mathrm{HNO}_{3}$ and the volume completed with propan-1ol in $10 \mathrm{~mL}$ volumetric flasks, was found to be homogeneous

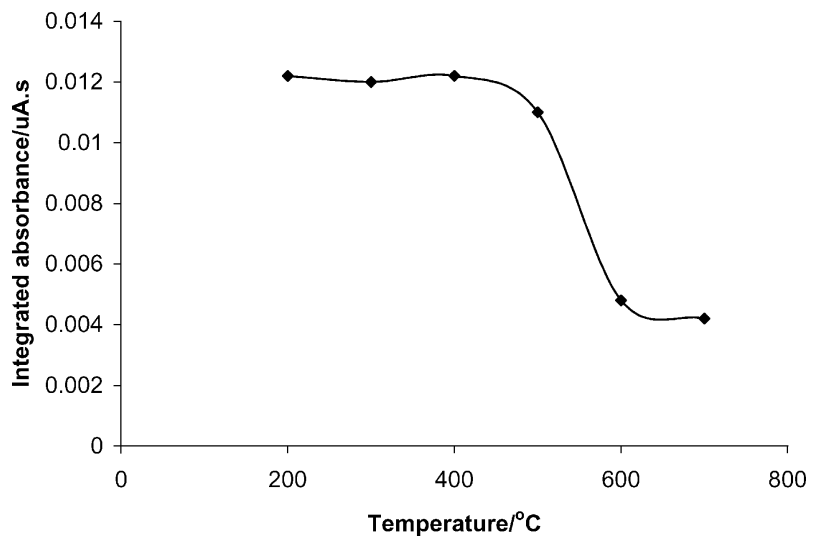

Fig. 1 Pyrolysis curve for for a $\mathrm{Hg} 30 \mathrm{mg} \mathrm{L}^{-1}$ standard in microemulsion using Pd chemical modifier and the conditions as recommended by the instrument manufacturer for determination of $\mathrm{Hg}$.

and stable for more than $1 \mathrm{~h}$. Blank solutions were prepared in the same way with xylene replacing the sample.

\subsection{Optimization of ETAAS temperature program}

In order to optimize the instrumental conditions, pyrolysis curves were carried out, maintaining constant the other conditions as recommended by the instrument manufacturer for determination of $\mathrm{Hg}$. The maximum pyrolysis temperature was $400{ }^{\circ} \mathrm{C}$ to guarantee that most of the matrix would be eliminated, without loss of the analyte, as can be seen in Fig. 1. Significant loss of $\mathrm{Hg}$ is observed when temperatures above of $400{ }^{\circ} \mathrm{C}$ were applied. The atomization curve was also obtained and the best temperature was found to be $1400{ }^{\circ} \mathrm{C}$ as shown in Fig. 2. The optimized temperature program (Table 2) was used for the determination of $\mathrm{Hg}$ in petroleum product samples.

\subsection{Major figures of the proposed method}

Calibration curves were established using organic and aqueous standards, using the optimized experimental and instrumental parameters for the determination of $\mathrm{Hg}$. The slopes of the calibration curve using inorganic and organic standards were similar (Table 3). This means that $\mathrm{Hg}$ in naphtha can be determined using the standard calibration technique with inorganic standards. Simple calibration was used to collect sample data and the calibration curves for $\mathrm{Hg}$ using inorganic

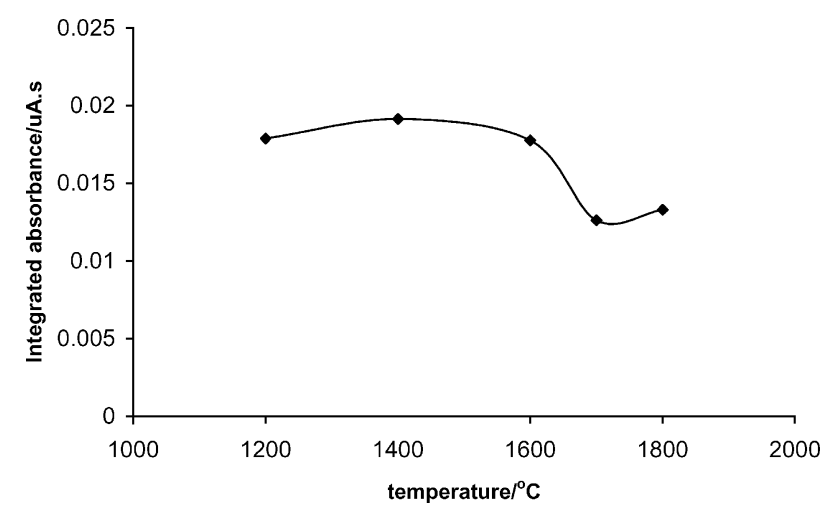

Fig. 2 Atomization curve for a $\mathrm{Hg} 30 \mathrm{mg} \mathrm{L}^{-1}$ standard in microemulsion using Pd chemical modifier. 
Table 3 Calibration equations and correlation coefficients for $\mathrm{Hg}$ determination in naphtha using micro-emulsions and multiple injections

\begin{tabular}{lll}
\hline Calibration & Equation & $\begin{array}{l}\text { Coefficient of } \\
\text { correlation }\end{array}$ \\
\hline $\begin{array}{l}\text { Analytical curve using } \\
\text { organic standard }\end{array}$ & $Y=0.0004 X+0.0062$ & 0.9927 \\
$\begin{array}{l}\text { Analytical curve using } \\
\text { inorganic standard }\end{array}$ & $Y=0.0004 X+0.0008$ & 0.9926 \\
\hline
\end{tabular}

Table 4 Mercury concentration obtained in spiked naphtha samples

\begin{tabular}{llrl}
\hline Sample & Added $/ \mu \mathrm{g} \mathrm{L}^{-1}$ & Found $/ \mu \mathrm{g} \mathrm{L}^{-1}$ & Recovery (\%) \\
\hline Naphtha 1 & 0 & $7.0 \pm 0.5$ & - \\
& 7.0 & $15.0 \pm 0.5$ & 114 \\
Naphtha 2 & 0 & $8.6 \pm 0.3$ & - \\
Naphtha 3 & 0 & $15.0 \pm 0.4$ & 91 \\
& 7.0 & $14.0 \pm 0.5$ & - \\
Naphtha 4 & 0 & $20.5 \pm 0.6$ & 93 \\
\hline
\end{tabular}

standards in propan-1-ol showed a linear response up to analyte concentrations of $150 \mu \mathrm{g} \mathrm{L}^{-1}$ with a correlation coefficient of 0.993 . The precision (repeatability) calculated from fifteen consecutive measurements, and defined as the coefficient of variation, of solutions containing 5.0 and $30 \mu \mathrm{g} \mathrm{L}^{-1}$ of $\mathrm{Hg}$ was $6.4 \%$ and $4.7 \%$, respectively. The limit of detection (LOD), defined as the $\mathrm{Hg}$ concentration that gives a response equivalent to three times the standard deviation $(s)$ of the blank ( $n=10)$, was found to be $0.78 \mu \mathrm{g} \mathrm{L}^{-1}$. As can be seen, a low limit of detection and a very good sensitivity for mercury determination in an organic matrix were obtained. Such figures of merit are comparable to that obtained by ICP-MS.

\subsection{Analytical application}

Four naphtha samples taken from different lots were analyzed for mercury under the recommended analytical settings. The results are shown in Table 4 . Three samples were spiked with $7.0 \mu \mathrm{g} \mathrm{L}^{-1}$ of $\mathrm{Hg}$, resulting a in recovery value varying between 91 and $114 \%$, thus indicating reasonable accuracy considering the complex matrices analyzed in this work. Sample spiking was used for accuracy assessment, since a standard reference material is not available neither in naphtha or in a suitable matrix such as xylene, toluene, light oils, etc. Additionally, no standard method for mercury determination in naphtha, which could be used as a comparative method, was found.

\section{Conclusions}

A method for trace determination of mercury in naphtha samples with direct preconcentration employing multiple in- jections in the graphite tube was developed using electrothermal atomic absorption spectrometry. The method is simple, fast and does not require the sample to be subjected to any drastic or time-consuming pretreatment, such as concentrated acids heating.

\section{Acknowledgements}

The authors are grateful to the Brazilian research funding agencies CNPq (Conselho Nacional de Desenvolvimento Científico e Tecnológico), FINEP/CTPetro (Financiadora de Estudos e Projetos), FAPESB (Fundação de Amparo à Pesquisa do Estado da Bahia) and Braskem S. A. for supplying technical resources required for this work.

The authors wish also to thank for the valuable support of S. L. C. Ferreira, M. G. R. Vale and B. Welz.

\section{References}

1 M. Turunen, S. Peraniemi, M. Ahlgrén and H. Westerholm, Anal. Chim. Acta, 1995, 311, 85-91.

2 S. M. Wilhelm, L. Liang and D. Kirchgessner, Energy Fuels, 2006, 20, $180-186$.

3 S. M. Wilhelm and N. Bloom, Fuel Process. Technol., 2000, 63, 127.

4 O. Platteau and M. Carrillo, Fuel, 1995, 74, 761-767.

5 H. E. Knauer and G. E. Milliman, Anal. Chem., 1975, 47, 12631268.

6 L. Liang, M. Horvat and P. Danilchik, Sci. Total Environ., 1996, 187, 57-64.

7 M. V. Reboucas, S. L. C. Ferreira and B. de Barros Neto, J. Anal. At. Spectrom., 2003, 18, 1267-1273.

8 S. J. Kumar and S. Gangdharran, J. Anal. At. Spectrom., 1999, 14, 967-971.

9 W. N. L. dos Santos, F. S. Dias, M. S. Fernandes, M. V. Reboucas, M. G. R. Vale, B. Welz and S. L. C. Ferreira, J. Anal. At. Spectrom., 2005, 20, 127-129.

10 N. N. Meeravali and S. J. Kumar, J. Anal. At. Spectrom., 2001, 16, $527-532$.

11 A. F. da Silva, B. Welz and A. J. Curtius, Spectrochim. Acta, Part $B, 2002,57,2031-2045$.

12 G. P. Brandão, R. C. de Campos and A. S. Luna, Spectrochim. Acta, Part B, 2005, 60, 625-631.

13 S. M. Wilhelm, L. Liang and D. Kirchgessner, Energy Fuels, 2006, 20, $180-186$.

14 C. H. Conaway, R. P. Mason, D. J. Steding and A. R. Flegal, Atmos. Environ., 2005, 39, 101-105.

15 L. Liang, M. Horvat, V. Fajon, N. Prosenc, H. Li and P. Pang, Energy Fuels, 2003, 17, 1175-1179.

16 W. R. Kelly, S. E. Long and J. L. Mann, Anal. Bioanal. Chem., 2003, 376, 753-758.

17 B. Bouyssiere, F. Baco, L. Savary and R. Lobinski, J. Chromatogr., A, 2002, 976, 431-439.

18 N. S. Bloom, Fresenius' J. Anal. Chem., 2000, 366, 438-443.

19 L. Liang, S. Lazoff, M. Horvat, E. Swain and J. Gilkeson, Fresenius' J. Anal. Chem., 2000, 367, 8-11. 